\title{
ENGINEERING DESIGN AND STRENGTH ANALYSES OF MAIN LOAD- BEARING PARTS OF A MECHANICAL RACK SYSTEM
}

\author{
Miroslav BLATNICKÝ ${ }^{1}$, Ján DIŽO ${ }^{1}$, Dalibor BARTA ${ }^{1}$, Pawel DROZDZIEL ${ }^{2}$ \\ ${ }^{1}$ University of Žilina, Faculty of Mechanical engineering, Department of Transport and Handling Machnines, \\ Univerzitná 8215/1, 01026 Žilina, Slovak Republik, e-mail: miroslav.blatnicky@fstroj.uniza.sk, \\ jan.dizo@fstroj.uniza.sk, dalibor.barta@fstroj.uniza.sk \\ ${ }^{2}$ Lublin University of Technology, Faculty of Mechanical Engineering, Department of Transport, Combustion \\ Engines and Ecology, ul. Nadbystrzycka 36, 20-618 Lublin, Poland, e-mail: p.drozdziel@ pollub.pl
}

Abstract

This article presents an engineering design of a mechanical rack system along with strength analyses of its main load-bearer parts. The designed mechanical rack system is intended to be mounted in a production hall for storage of rod material with total length of $6 \mathrm{~m}$. The whole structure of this equipment is welded and made of steel profiles. It consists of a main load-bearing part, which comprises a central beam and horizontal beams and four draw-out shelves on each side, which are arranged four levels. Every individual shelve is able to carry the mass of $3.0 \mathrm{t}$. As the solved rack system is not standardized but designed in compliance with specific requirements of a customer, we had to support the structure carrying capacity with strength calculations. Structural calculations were realized by means of numeric finite element method. Strength analyses were performed for the maximum load cases.

Keywords: mechanical rack system, storage of a goods, strength calculations, finite element method

\section{INTRODUCTION}

Storage cannot be separated from material flows in all spheres of economy. The need for storage of material of all kinds arises due to the different pace of production and consumption, the different flow in all levels of a logistic chain. Moreover, the storage forms an inevitable part of the production technology. We can deal with warehouse issues in different ways, with reference to building solutions, the organization, technical equipment and many others. From the point of view of logistic objects it is particularly suitable to pay attention to three types of warehouses, namely the warehouse of bulk material, metallurgical material and pallets. Material characteristics, material amount, and storage technology requirements in connection with other processes are essential for the right choice of warehouses. In analysing the kind of metallurgical material in a certain engineering company it was found out that only $25 \%$ of items are material of one item in bulk with a large turnover rate of revenues and costs. The rest of material weighed less though their items formed $70 \%$ up to $80 \%$ of the whole items in that warehouse. That's why it is necessary to provide with optimal conditions for storage and handling and at the same time it is simple to solve the technology of handled items off take. Such quantities of rod material are to be stocked in racks (Fig. 1) and we recommend seizing them by means of a grab bucket. Using this way of handling we do not need to bind material and in terms of controlling it is very suitable.

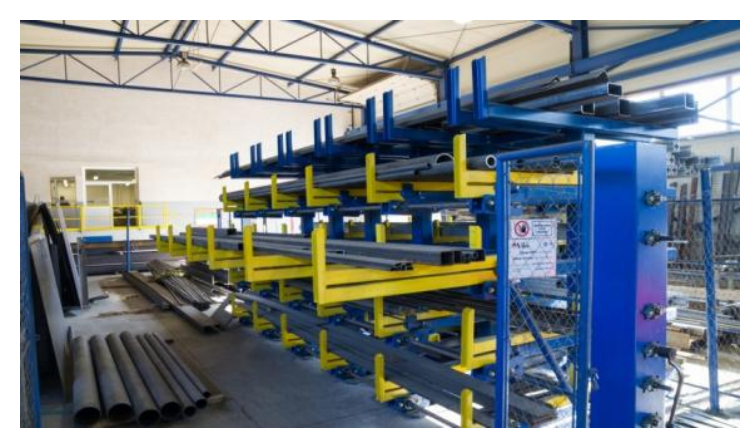

Fig. 1. The mechanical rack system

\section{FUNDAMENTALS OF A SOLVED PROBLEM}

Generally, handling equipment consists of bearing construction, driving mechanism and other parts (various additional equipment, e.g. a cab). The steel strucutre forms a basic bearing part of any handling equipment. Mostly it means the bearing construction of all equipment working parts which transmits all external loads affecting the equipment. The shape of the steel structure defines its kind and purpose of use. Its production is carried out by joining parts into larger structures by means of either riveting (an older way), or welding (nowadays the most common way). For this reason, the designed steel structure of a rack system will be 
constructed by welding. Among the most important customer's requirements we can include the safety of the structure. The steel structure should be light and rigid enough to ensure the economy of production and operation, it should also be aesthetic and take into account the perfect arrangement of the steel structure as a whole, it should allow a safe access to all mechanisms, and it should also have an appropriate division with regard to its assembly.

In designing the steel structure we consider particularly safety and consequently, reliability (summary of characteristics and factors which affect usability, no-failure operation, and maintenance of the steel structure) [3]. The structure will be formed by means of welding and we have to ensure the welding capability of material. Welding steel without special requirements and welding conditions (due to the demand for the economy of production) cannot contain more than $0,18 \%$ of carbon resulting in strength less than $400 \mathrm{MPa}$ of the given classes of steel used for the steel structures. To increase strength we can use steel with other alloyed element, for example steel 11523 has strength 520 $\mathrm{MPa}$ and is alloyed by manganese (max: $1,5 \% \mathrm{Mn}$, $0,55 \% \mathrm{Si}, 0,3 \% \mathrm{Cr}, 0,3 \% \mathrm{Ni}$ ) [1]. That's why we have chosen steel S235 and S355 as basic material of rack system structure. In welded structures influenced statically and dynamically we use butt and fillet welds. The calculation is run on dimension principles with certain specification. To save storage area, for the company it is important that the rack, serving for material storage, provides the storage in several layers in height. To alleviate handling with material stored in the rack and to increase clarity, one kind of material is deposited together if possible. Moreover, we have to take into account the principle that if we put more kinds of material into the rack, loading and unloading of material at the bottom is time-consuming. Therefore, to increase the handling efficiency it is advisable to construct storage racks as a mechanism with a single degree of freedom, which allows to pull out the material horizontally and to grip it by means of a grab bucket.

\section{DESIGN OF A RACK SYSTEM}

The engineering design of steel structure consists of three elements (Fig. 2), i.e. load-bearing structure of central, vertical and horizontal beams, into which racks are pulled in and out, are welded to this structure. The storage method ensures demanded movement possibilities, i.e. the rack movement. The material in weight of 3.0 tons will be stored on eight retractable racks. Each retractable rack is divided into six parts - webs mutually connected with shafts by means of shaft coupling and they are pulled out together by a crank handle.

Working with the sixths model means to save calculation because the structure is designed symmetrically from the view of geometry, fixing and loading. The steel structure is made from thinwalled square tubing which dimensions and materials are put in Table 1.

Table 1. Individual parts of the designed structure

\begin{tabular}{|r|r|r|}
\hline Main parts & Dimensions [mm] & Material \\
\hline Centre beam & $160 \times 160 \times 10$ & S235 \\
\hline Horizontal beam & $100 \times 80 \times 6$ & S355 \\
\hline Shelves & $80 \times 60 \times 4$ & S355 \\
\hline
\end{tabular}

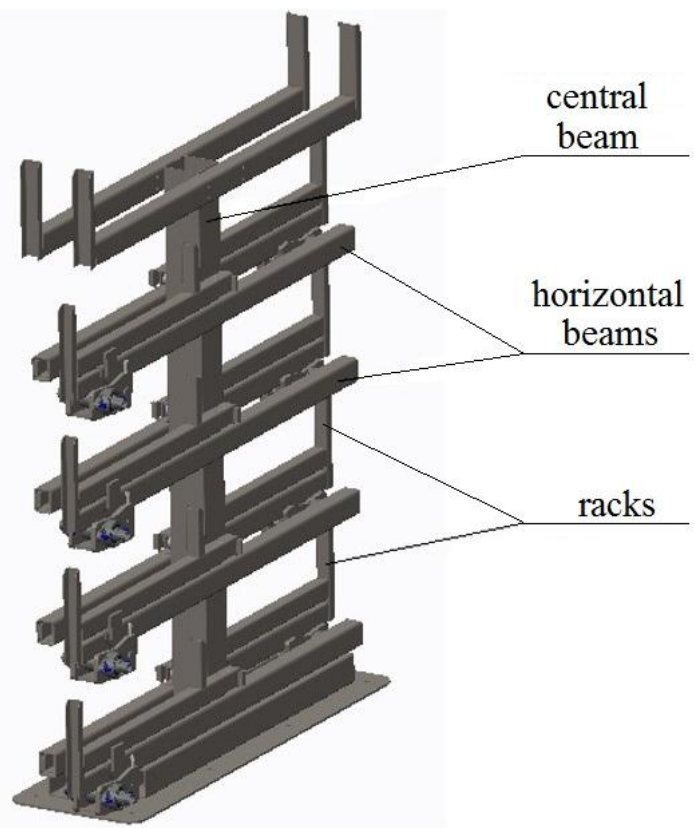

Fig. 2. Main load-bearing parts of the designed rack system

Mechanical properties of used materials whose knowledge is necessary for the structure analysis are listed in Table 2.

Table 2. Mechanical properties of used materials [1]

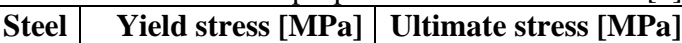

\begin{tabular}{l|r|r|} 
S235 & $200-240$ & $340-420$ \\
\hline S355 & $320-360$ & $520-640$ \\
\hline
\end{tabular}

Whereas the transmission of structure mechanism is driven by a crank handle, the racks will move forward at low speed, so the dynamic stress of the structure is not significant. We count the maximum of allowed stress according to (1):

$$
R_{p e r}=R_{e} \cdot \frac{1}{k} .
$$

We consider for material yield strength of horizontal beams and racks $R_{e}=360 \mathrm{MPa}$ and safety coefficient with regard to the static way of loading the structure $k=1.7(-)$. For material yield strength of central beams we consider $R_{e}=240 \mathrm{MPa}$ and the safety coefficient with regard to the static way of loading the structure as well as in the previous case $k=1.7(-)$. Then for allowed stress in the structure by using material S355 we get using (1) following: 


$$
R_{p e r}^{355}=R_{e}^{355} \cdot \frac{1}{k}=360 \cdot \frac{1}{1.7} \doteq 211.8 M P a
$$

and for material S235 $R_{\text {per235 }}=141 \mathrm{MPa}$ :

$$
R_{p e r}^{235}=R_{e}^{235} \cdot \frac{1}{k}=240 \cdot \frac{1}{1.7} \doteq 141.2 M P a .
$$

In the locations of weld of each structural part it is necessary to decrease in the allowed stress of the amount which is experimentally practiced and decreases in the allowed stress of approximately $30 \%$. We include this fact in the calculation by using the welding coefficient $c$ :

$$
R_{p e r W}=R_{p e r} \cdot c .
$$

To reduce the allowed stress amount in the place of weld by recommended $30 \%$ we choose the amount of welding coefficient $c=0.7(-)$. By solving the equation (4) we get permissible values of stress in the location of welds for the S355 material following:

$$
R_{p e r W}^{355}=R_{p e r}^{355} \cdot c=211.8 \cdot 0.7 \doteq 148.3 \mathrm{MPa}
$$

and for the $\mathrm{S} 235$ material:

$$
R_{\text {perW }}^{235}=R_{\text {per }}^{235} \cdot c=141.2 \cdot 0.7 \doteq 98.8 \mathrm{MPa} \text {. }
$$

The realization of the mechanism for webs movement will be carried out by means of a friction wheel and we will expect low initial costs because its production technology is not really difficult. Moreover, there is no need for much maintenance because it is not necessary to lubricate, even it is not allowed. Another main advantage is a low frequency of failure rate.

Hand drive is not suitable for all mechanisms because we should take into account person`s performance and comfort. We can use it only for a small load capacity, a low lift, and low working speeds during the occasional, not permanent use. When designing the hand drive, we have to remember that the permanent performance of an average person is about $75 \mathrm{~W}$. And as well, we have to take into account the ergonomic point so that a worker can use the equipment without any difficulty. The best way of transferring strength is by a handle at maximum circumferential speed of $1 \mathrm{~m} / \mathrm{s}$. During the permanent work of one worker (considering his performance) the force on the crank is set to the maximum of $100 \mathrm{~N}$. It is also possible to increase the force up to $200 \mathrm{~N}$ during 10 minutes, of course in case of reducing the speed.

\section{CALCULATION OF FORCES LOADING THE STRUCTURE}

As the first step there is necessary to determine forces loading the designed structure. There act gravitational forces of individual parts and loads on arms and also reactions. Reactions depend on arm overhang. We come out from diagrams shown in Fig. 3 and Fig. 4. Every shelve is supporting on three rolling bearings marked in Figures with letters $\mathrm{A}, \mathrm{B}$ and $\mathrm{C}$. From the working principle of the rack system, there are two extreme loading position, i. e. when arms are in the pulling-in (Fig. 3) and pullingout (Fig. 4) positions. In diagrams, acting forces (red colour) and reactions (green colour) are depicted. As we can notice, in the pulling-in position reactions arise only in the $A$ and $B$ bearings and in the pulling-out positions, reactions arise in the $A$ and $C$ bearings while the $B$ bearing is loaded no more.

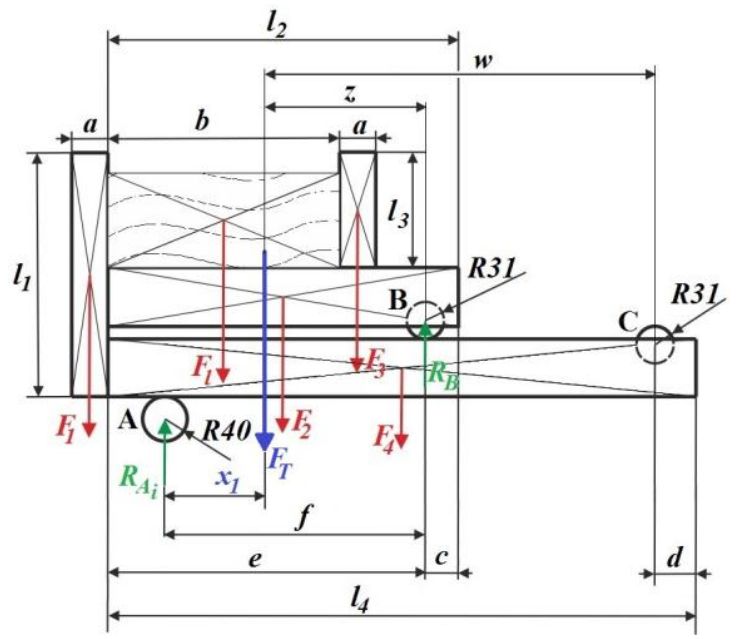

Fig. 3. Releasing diagram of the mechanism for pulling-in position of the shelve

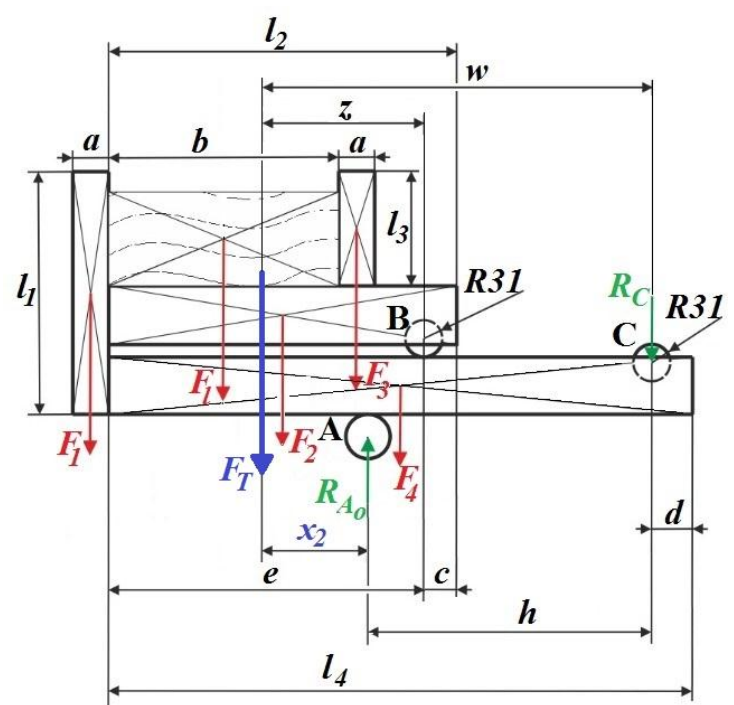

Fig. 4. Releasing diagram of the mechanism for pulling-out position of the shelve

Parameters of the mechanism dimensioning in Fig. 5 and Fig. 6 are listed in Table 3.

Table 3. Basic parameters of the mechanism

\begin{tabular}{|l|r|c|r|}
\hline $\boldsymbol{a}$ & $40 \mathrm{~mm}$ & $\boldsymbol{l}_{\boldsymbol{I}}$ & $400 \mathrm{~mm}$ \\
\hline $\boldsymbol{b}$ & $900 \mathrm{~mm}$ & $\boldsymbol{l}_{\boldsymbol{2}}$ & $1,200 \mathrm{~mm}$ \\
\hline $\boldsymbol{c}$ & $82 \mathrm{~mm}$ & $\boldsymbol{l}_{\boldsymbol{3}}$ & $200 \mathrm{~mm}$ \\
\hline $\boldsymbol{d}$ & $103 \mathrm{~mm}$ & $\boldsymbol{l}_{\boldsymbol{4}}$ & $2,095 \mathrm{~mm}$ \\
\hline $\boldsymbol{e}$ & $1,118 \mathrm{~mm}$ & $\boldsymbol{z}$ & $643 \mathrm{~mm}$ \\
\hline $\boldsymbol{h}$ & $917 \mathrm{~mm}$ & $\boldsymbol{w}$ & $1,517 \mathrm{~mm}$ \\
\hline $\boldsymbol{f}$ & $958 \mathrm{~mm}$ & & \\
\hline
\end{tabular}

Dimensions $x_{1}$ and $x_{2}$ are variables and depend on the shelve overhanging. The dimension $x_{1}$ acquires values form the interval $\langle 0,315.0 \mathrm{~mm}\rangle$ 
and the dimension $x_{2}$ from the interval $\langle 0,600.0 \mathrm{~mm}\rangle$.

For next calculations we have to determine reactions $\left(R_{A i}, R_{A o}, R_{B}\right.$ and $\left.R_{C}\right)$ in supporting bearings as following. Firstly it is necessary to calculate gravitational forces of individual parts of the arm $\left(F_{1}, F_{2}, F_{3}\right.$ and $\left.F_{4}\right)$ and of the load $\left(F_{l}\right)$. We follow the familiar formula:

$$
F_{i}=m_{i} \cdot g \text {, }
$$

where

$$
m_{i}=l_{i} \cdot m_{i}^{\prime}, \text { for } i=1,2,3,4
$$

while $m_{i}^{\prime}$ are masses of individual profiles per unit of length introduced in Table 4 and $g$ is the gravitational acceleration.

Table 4. Masses of profiles per unit of length

\begin{tabular}{|l|r|c|r|}
\hline$m_{1}^{\prime}$ & $4.915 \mathrm{~kg} / \mathrm{m}$ & $m_{3}^{\prime}$ & $4.915 \mathrm{~kg} / \mathrm{m}$ \\
\hline$m_{2}^{\prime}$ & $9.830 \mathrm{~kg} / \mathrm{m}$ & $m_{4}^{\prime}$ & $9.830 \mathrm{~kg} / \mathrm{m}$ \\
\hline
\end{tabular}

As we consider the sixths model, also gravitational force of the load is sixths. If we take into account the gravitational acceleration of $9.81 \mathrm{~m} / \mathrm{s}^{2}$ and values of dimensions and masses written in Table 3 and Table 4, respectively, gravitational forces are: $F_{l}=19.29 \mathrm{~N}$, $F_{2}=115.72 \mathrm{~N}, \quad F_{3}=9.64 \mathrm{~N}, \quad F_{4}=202.03 \mathrm{~N}$ and $F_{l}=4,905.0 \mathrm{~N}$.

Now, it is relatively simple to determine value and position of the total gravitational force $F_{T}$ acting on the one sixths of the arm structure. Its value is $5,251.68 \mathrm{~N}$ and and position is obvious from Fig. 3 and Fig. 4.

Reactions in supporting bearings we calculate using equations of equilibrium of moments in individual points. The sum of moments in the point $B$ for the arm position according to Fig. 3 is:

$$
\sum M i_{B}=0, \Rightarrow R_{A i} \cdot\left(l-x_{1}\right)-F_{T} \cdot z=0,
$$

From this equation we get the reaction $R_{A}$ :

$$
R_{A i}=F_{T} \cdot\left(\frac{z}{l-x_{1}}\right)
$$

When the arm is still pulling-out, distribution of acting forces will be different and that according to Fig. 4. Then, the reaction in bearing $A$ will be marked as $R_{A o}$ and it will be calculated from the different equation of moment's equilibrium. It means, that we come out form following formula:

$$
\sum M i_{C}=0, \Rightarrow R_{A^{\prime}} \cdot\left(w-x_{2}\right)=F_{g} \cdot w,
$$

from which

$$
R_{A^{\prime}}=F_{g} \cdot\left(\frac{w}{w-x_{2}}\right)
$$

Next, we determine other reactions. For the calculation of the reaction $R_{B}$ we compile the sum of moments in the point $A$ :

$\sum M i_{A}=0, \Rightarrow R_{B} \cdot\left(l-x_{1}\right)-F_{T} \cdot\left(l-z-x_{1}\right)=0$,

thus:

$$
R_{B}=F_{T} \cdot \frac{\left(l-z-x_{1}\right)}{\left(l-x_{1}\right)}
$$

Finally, the reaction $R_{C}$ we get from the sum of moments in the point $A$ in the pulling-out positon following:

$$
\begin{gathered}
\sum M i_{A}=0, \Rightarrow F_{T} \cdot x_{2}-R_{C} \cdot\left(w-x_{2}\right)=0, \\
R_{C}=F_{g} \cdot\left(\frac{x_{2}}{w-x_{2}}\right)
\end{gathered}
$$

As we can see, reactions depend on dimensions $x_{1}$ and $x_{2}$. Calculated values of reactions are wellarranged listed in Table 5.

Table 5. Calculated values of reactions

\begin{tabular}{|c|c|c|}
\hline & Reaction & {$[\mathrm{N}]$} \\
\hline \multirow{2}{*}{$x_{I}=0 \mathrm{~mm}$} & $R_{A i}$ & $3,501.5$ \\
\cline { 2 - 3 } & $R_{B}$ & $1,715.5$ \\
\hline \multirow{2}{*}{$x_{I}=315 \mathrm{~mm}$} & $R_{A i}$ & $5,217.0$ \\
\cline { 2 - 3 } & $R_{B}$ & 0.0 \\
\hline \multirow{2}{*}{$x_{2}=0 \mathrm{~mm}$} & $R_{A o}$ & $5,217.0$ \\
\cline { 2 - 3 } & $R_{C}$ & 0.0 \\
\hline \multirow{2}{*}{$x_{2}=600 \mathrm{~mm}$} & $R_{A o}$ & $8,630.0$ \\
\cline { 2 - 3 } & $R_{C}$ & $3,413.5$ \\
\hline
\end{tabular}

By the above procedure we have calculated reactions, i. e. forces, which will serve as necessary input for numerical calculations of main.

\section{STRENGTH ANALYSES OF MAIN LOAD- BEARING PARTS USING FEM}

The strength analyses of main load-bearing parts of the rack system were carried out in the ADINA software by using known Finite Element Method [5, 10, 11]. As the structure consists of thin-walled tubing, it is suitable for the model creating to use shell elements.
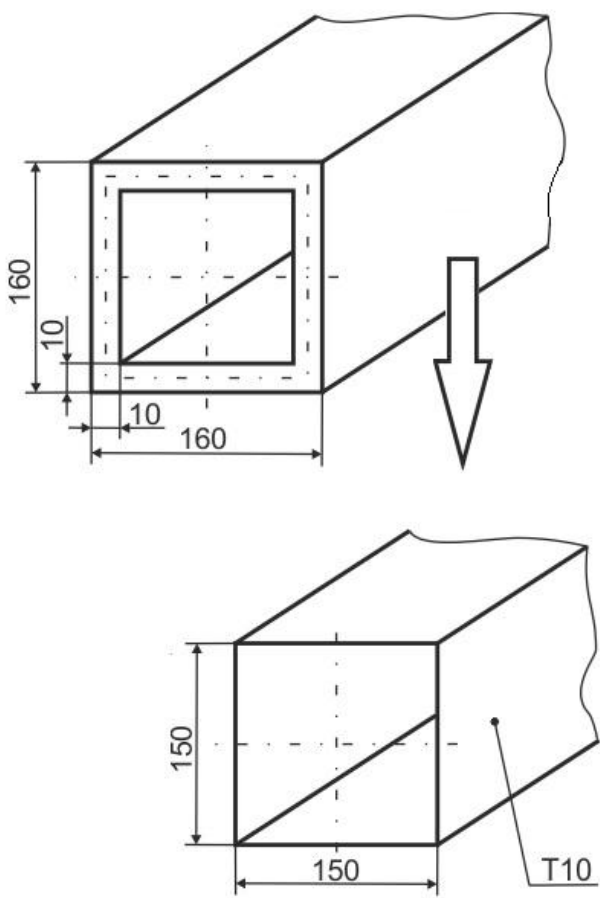

Fig. 3. Proces of shell model preparing 
While modelling the shells it is necessary to prepare the geometric model with modified dimensions in advance. We have used so-called mid-surface and we have added the thickness of material (Fig. 3).

In ADINA Structures Pre-Processing [2, 4] we created the geometry of the shell model of the investigated part (Fig. 4).

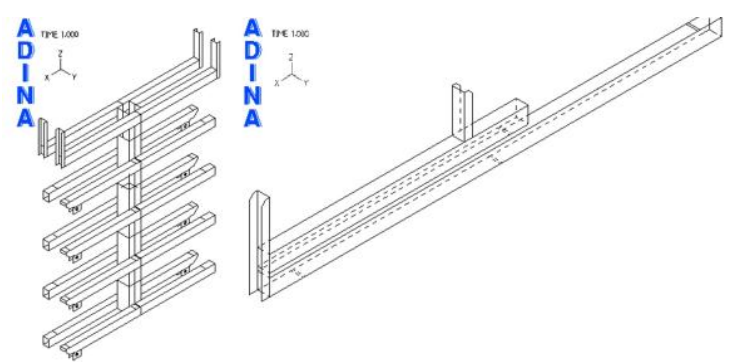

Fig. 4. Geometry of the rack load-beaging part (left) and the rack arm (right)

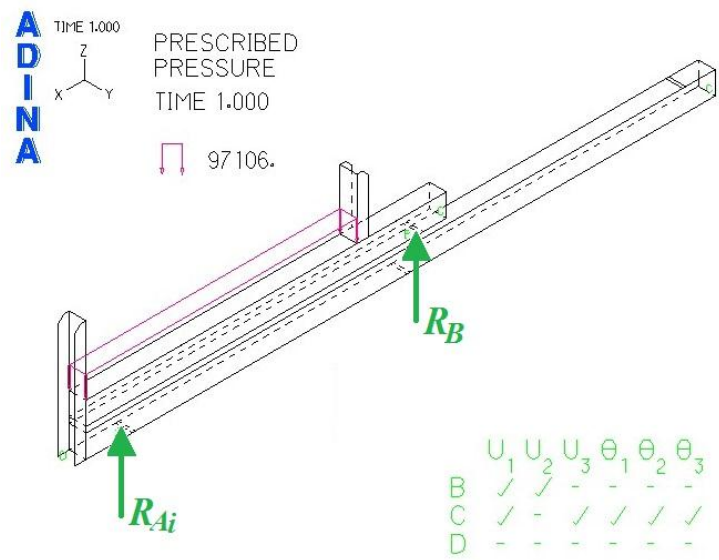

Fig. 5. Load forces and boundary conditions for pulled-in position of the arm

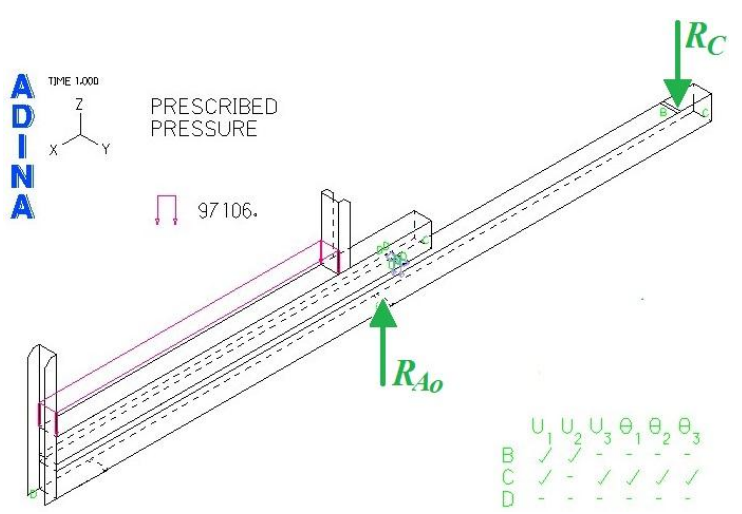

Fig. 6. Load forces and boundary conditions for pulledout position of the arm

The mechanism can be placed in two extreme positions when the arm is pulled-in (Fig. 5) and pulled-out position (Fig. 6), where forces $F_{\mathrm{Ai}}, F_{B}$, $F_{A o}$ and $F_{C}$ are forces loading the structure and they values were calculated in previous analytical calculations (Chapter 4). In numerical calculations the load is defined in the same way as in the reality, i. continuous load (in comparison with the force vector in analytical calculations).

By reason of various loads in just mentioned two extreme positions we have analysed the structure twice. As the structure is made of steel, we choose elastic isotropic material model with corresponding mechanical properties: Young`s modulus of tensile elasticity $E=2.1 \cdot 10^{11} \mathrm{~Pa}$, Poisson's coefficient $\mu=0.33(-)$, density of material $\rho=7,850 \mathrm{~kg} / \mathrm{m}^{3}$.

The attachment of the model was performed by removing all degrees of freedom except of movements in $x$ and $y$ directions at the lower rims of the central beam by applying one edge point of the lower rim and removing one level of freedom in $x$ direction at the opposing point. And we continued in forming the group of finite elements. A single group of shell elements with certain thickness was created for each part of the model with different thickness of a wall. Then it was necessary to create a group of rod elements (Fig. 7) which filled in the lifting hole in order to apply the loading forces in the middle of the lifting hole.

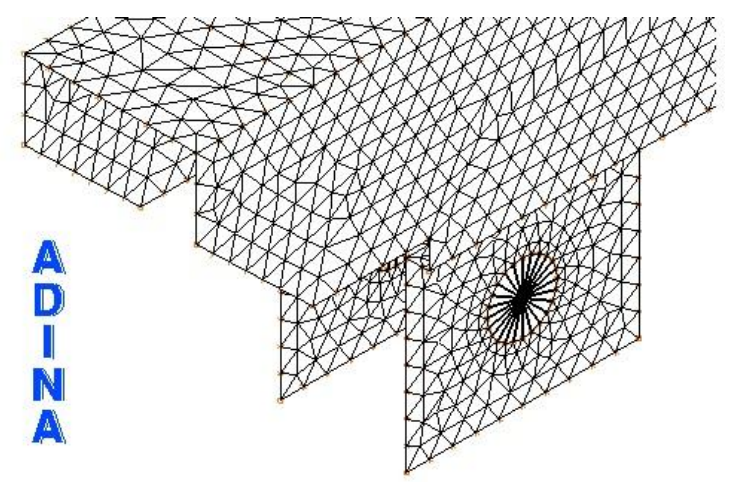

Fig. 7. Detail of FE mesh in the lifting hole

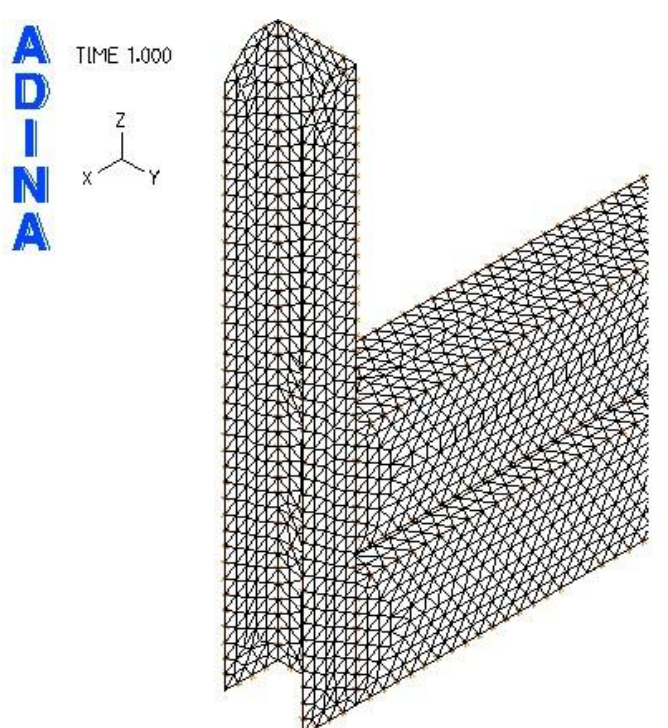

Fig. 8. Ilustration of the FE mesh of the analysed strucutre parts

Taking into account the compromise between accuracy of the calculation and needed calculation 
we set the size of elements to $10 \mathrm{~mm}$. Finally the model was meshed by linear tetrahedrons (Fig. 8).

After defining parameters and setting-up the FE model of the structure there is possibly to perform analyses. Then, it is necessary to switch the programme to the module Post-Processing, in which all results of analyses are presented and evaluated $[5,8]$.

In time $t=1 \mathrm{~s}$, i.e. in the rack pulled-in position, stresses evaluated in compliance with the $\mathrm{HMH}$ hypothesis in the main-load bearing structure and in rack arms are distributed according to Fig. 9 and Fig. 10, respectively.

As we can see from these figures, in the pulledin position of arms the maximum stress in the loadbearing structure is of $86.67 \mathrm{MPa}$ except for the point of the attachment.

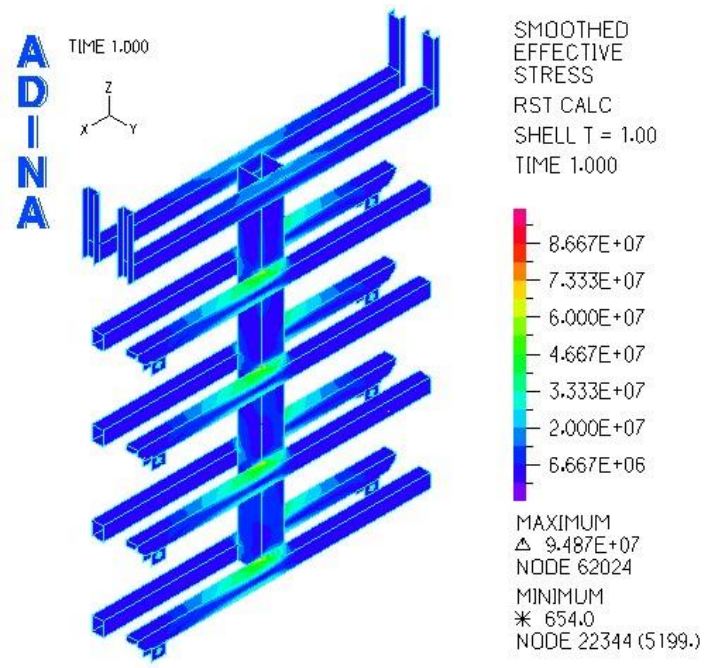

Fig. 9. Distribution of stresses in the central load-bearing part for the pulled-in position of arms

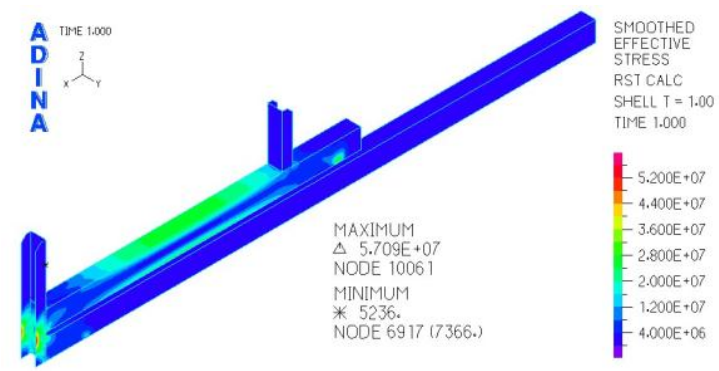

Fig. 10. Distribution of stresses in the arm for the pulled-in position of arms

The calculated value is smaller than the determined permissible stress for a welded structure (eq. 6), which is of 98.8 MPa. Thus, for the pulledin position the central load-bearing structure of the rack system is designed properly.

Looking at the Fig. 10 we observe, that the maximum stress in the analysed rack arm is of 57.09 MPa. But, we do not take into account this value, because this stress is in the point of applying the boundary condition. Actually, the stress according to the colour scale in figure is important. It is $52 \mathrm{MPa}$. In comparison with the permissible stress for a non-welded material (eq. 211.8 MPa) our results prove the correctness of the structure design.

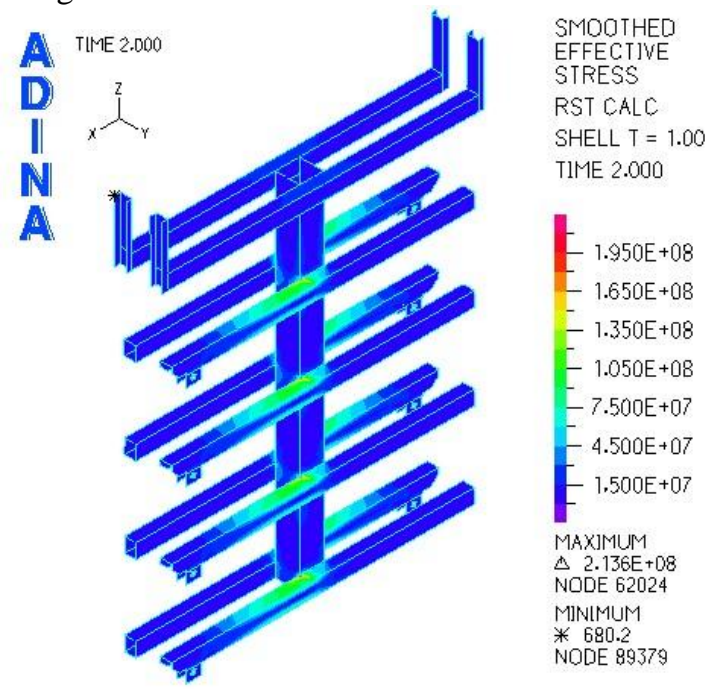

Fig. 11. Distribution of stresses in the central loadbearing part for the pulled-out position of arms

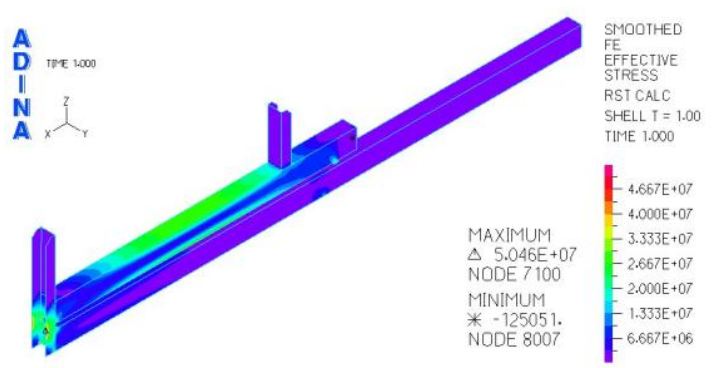

Fig. 12. Distribution of stresses in the arm for the pulledout position of arms

In time $t=2 \mathrm{~s}$, i.e. in pulled-out position of rack arms, the stress distribution in the central loadbearing structure and in rack arms calculated again according to the HMH hypothesis is shown in Fig. 11 and Fig. 12.

Let's a look in Fig. 11. The maximum of the calculated stress is $213.6 \mathrm{MPa}$ in the location of the attachment. The stress in the weld is $195 \mathrm{MPa}$. We cannot use the strength condition, because the calculated stress $(195 \mathrm{MPa})$ is bigger than the permissible values for welds (98.8 $\mathrm{MPa}$, eq. 6). On the other hand we can use the strength condition for the rack arm in the pulled-out. The maximum of the calculated stress almost $50 \mathrm{MPa}$ is acceptable even with sufficient allowance.

The strength analysis of the designed structure detected deficiencies of the design for the pulledout position of racks arms. By this reason it is necessary to perform some modifications of the structure.

\section{MODIFICATION OF THE CENTRAL LOAD-BEARING PART}

During solution of the modification problem of the central load-bearing part structure we have found out several possibilities, how to modify this 
structure. Taking into account all factors, as technological process of production, conservation of the structure simplicity, simple maintenance, production cost as well as requirements of customer, the optimal solution of this problem the complement of a supplementary sheet has turned out.

Such a sheet is placed between the central beam and horizontal beams such that the thickness is increased (Fig. 13).

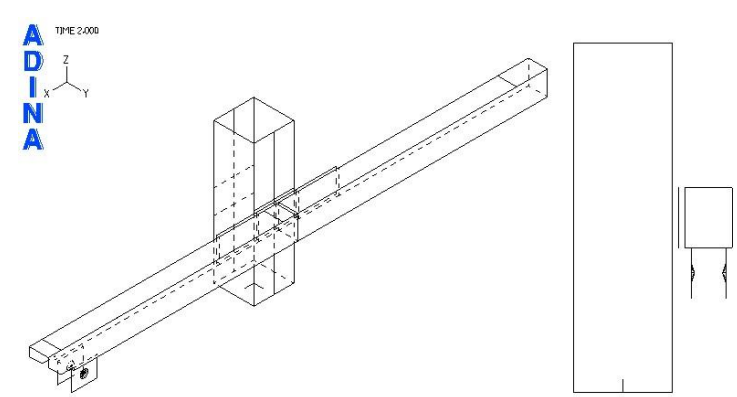

Fig. 13. Designed structural modification of the cetral load-bearing part

These all parts are coupled by welding. The thickness of a supplementary sheet is of $10 \mathrm{~mm}$ and it is made of $\mathrm{S} 355$ steel.

The geometry of load-bearing structure model is formed from three separated parts which are joined by means of interconnecting the displacements in each of the corresponding nodes of a mesh (Fig. 14). We have decided for this method, so that the model was more real. If only one mid-surface was modelled with the thickness of the corresponding amount of two beams and the sheet, the results would be less accurate because the sheet is welded to the beams only on the circuit and is not connected with the whole surface $[4,5]$.
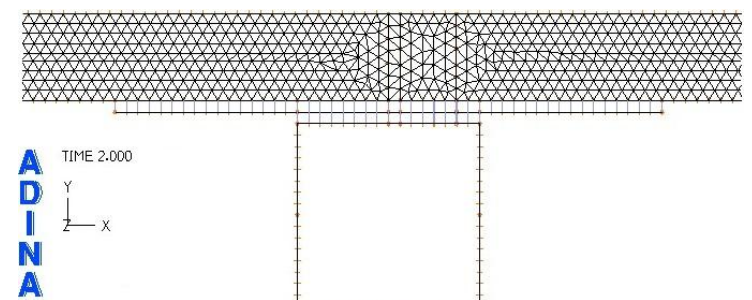

Fig. 14. Connctions of circuit nodes in the modified location

Results from reanalyses of the modified structure is shown in Fig. 15.

As we can see, designed modification of the structure results to the the stress reducing in the locations of the central beam and horizontal beams connection from $195 \mathrm{MPa}$ to $118.6 \mathrm{MPa}$.
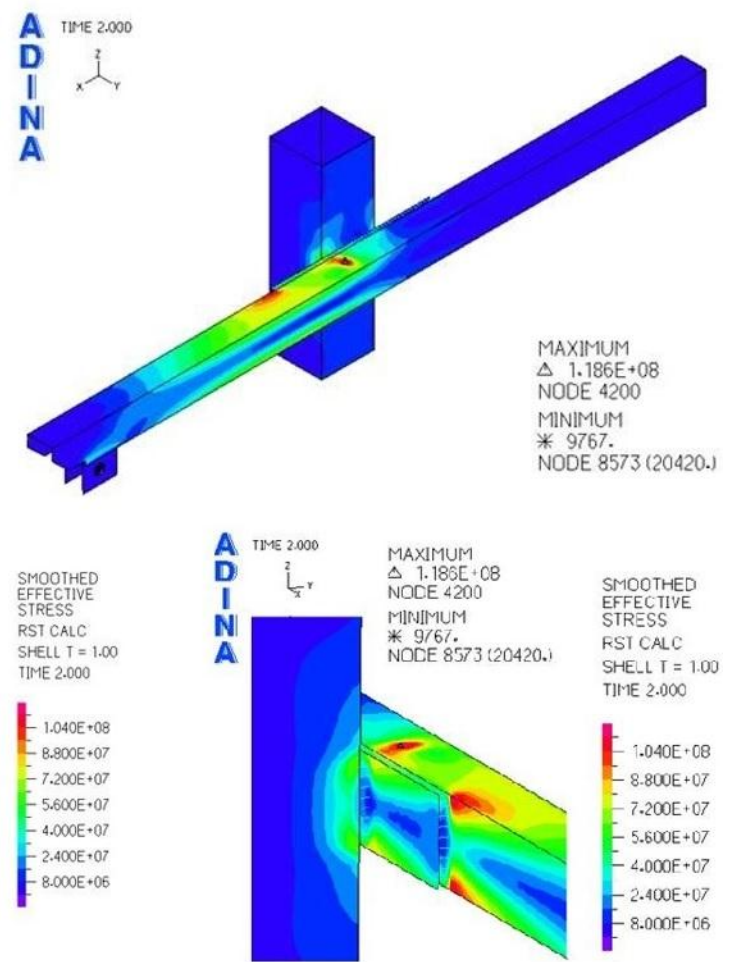

Fig. 15. Results of strength analysis of the modified central load-bearing part (above) and detail of the stress distribution in welded joint (below)

The comparison of obtained stress values with the permissible stress values for the welded material S 355 (148.3 MPa, eq. 5) we can conclude, that our designed modification of the analysed structure is proper and ensures the stress reducing in the overstrained locations to admissible values.

The maximum stress values will decrease to the safe value, and therefore the main load-bearing part of the rack system structure safely transmits required loads also during long-term operation.

In the case of necessity, further investigation of the designed rack system will be focused on settingup so-called flexible multibody system, which means that our FE model will be imported into the MBS software, where will be possible to study dynamic effects load on the structure resulting from the long-term operation conditions $[6,7,9]$.

\section{CONCLUSION}

This work presented technical solution of the mechanical rack system including strength analyses of its main load-bearing parts. The strength analyses were carried out in parts. The pull-out rack analysis has proved that this part of the structure does not meet the safety requirements. The analysis of the main load-bearing part of the structure showed significant deficiencies in strength and stability of the pulled-out rack position when the welds had the stress $213.6 \mathrm{MPa}$, and at the same time the arms are deformed. That is why we have designed the technical modification of the construction. This modification includes the weld 
between the central beam and horizontal beams and thus increases the thickness of the structure in most loaded locations. Based on numerical calculations we have found out, that our modification ensures stresses reducing on the acceptable value of 118.6 MPa.

\section{SOURCE OF FUNDING}

The work was supported by the Cultural and Educational Grant Agency of the Ministry of Education of the Slovak Republic in the project No. KEGA 077ŽU-4/2017: Modernization of the Vehicles and engines study program.

This contribution is the result of the project implementation: "Modern methods of teaching of control and diagnostic systems of engine vehicles", ITMS code 26110230107, supported by the Operational Programme Education.

\section{REFERENCES}

1. Bajla $J$, Bronček $J$, Antala $J$, Sekerešová D. Mechanical Engineering Tables. (In Slovak). Selection Standards. Slovak Office of Standards, Metrology and Testing. 2014.

2. Falendysh A, Volodarets M, Hatchenko V, Vykhopen I. Software analysis for modeling the parameters of shunting locomotives chassis. MATEC Web of Conferences, 2017;116. https://doi.org/10.1051/matecconf/201711603003

3. Galliková J, Stuchlý V, Poprocký R, Volna P. Model calculation of posterior reliability indicators for the proposal of the maintenance system. MATEC Web of Conferences, 2018; 157. https://doi.org/10.1051/matecconf/201815708003.

4. Gerlici J, Lack T, Harušinec J. Realistic simulation of railway operation on the RAILBCOT test stand. Applied Mechanics and Materials, 2014;486: 387395.

5. Handrik M, Vasko M, Kopas P, Saga M. Effective finite element solution and post-processing for wide load spectrum. Communications - Scientific letters of the University of Zilina 2014; 16(3a): 19-26.

6. Hauser V, Nozhenko O, Kravchenko K, Loulová M, Gerlici J, Lack T. car body and bogie connection modification for track curves passability improvement. MATEC Web of Conferences, $2018 ; 157$ https://doi.org/10.1051/matecconf/201815703009.

7. Hauser V, Nozhenko O, Kravchenko K, Loulova M, Gerlici J, Lack T. Proposal of a steering mechanism for tram bogie with three axle boxes. Procedia Engineering, 2017;192: 289-294. https://doi.org/10.1016/j.proeng.2017.06.050.

8. Kopas P, Saga M, Baniari V, Vasko M, Handrik M. A plastic strain and stress analysis of bending and torsion fatigue specimens in the low-cycle fatigue region using the finite element methods. Procedia Engineering 2017; 177: 526-531.

https://doi.org/10.1016/j.proeng.2017.02.256.

9. Sapietova A, Saga M, Shimanovsky A, Sapieta M. Mobility of multibody systems in terms of their incorrectness. Communications - Scientific letters of the University of Zilina 2014; 16(3a): 6-12.
10. Smetanka L, Gerlici J, Lack T, Pelagić Z. Homogenization of fibers reinforced composite materials for simulation analysis. Manufacturing Technology 2015; 15(5): 914-920.

11. Vatulia G, Falendysh A, Orel Y, Pavliuchenkov M. Structural Improvements in a Tank Wagon with Modern Software Packages. Procedia Engineering 2017; 187: 301-307. https://doi.org/10.1016/j.proeng.2017.04.379

Received 2018-06-08 Accepted 2018-10-26 Available online 2018-10-30

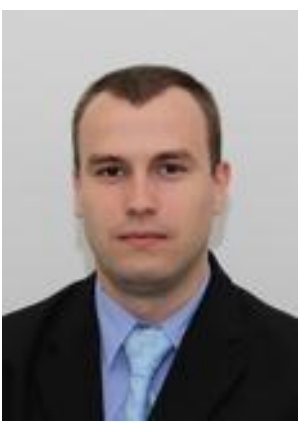

Ing. Miroslav BLATNICKÝ, $\mathrm{PhD}$. received M.Sc. and PhD. degrees in Mechanical Engineering from University of Žilina, respectively. $\mathrm{He}$ is currently teaching at the Faculty of Mechanical Engineering, University of Žilina. His area of research is focused on functional and strength calculations and FEM analyses in the field of transport and handling machines, hoisting machinery and steel structures.

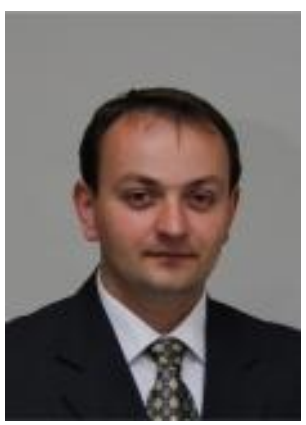

Ing. Ján DIŽO, $\mathrm{PhD}$. received B.Sc., M.Sc. and PhD. degrees in Mechanical Engineering from University of Žilina, respectively. $\mathrm{He}$ is currently teaching at the Faculty of Mechanical Engineering, University of Žilina. Mr. Dižo's research interest mainly focuses on creation of MBS models and analysing dynamic structural properties of transport and handling machines.

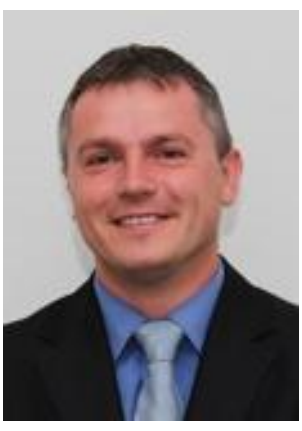

Doc. Ing. Dalibor BARTA, $\mathrm{PhD}$. is the university professor at the Department of Transport and Handling Machines of Faculty of Mechanical Engineering of University of Žilina. His scientific fields of interest relate to the simulation and design of non-convention drives of vehicles and using of alternative drives based on the real operating conditions.

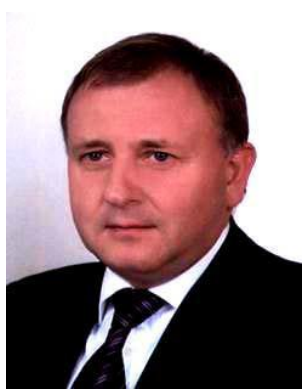

Dr hab. inż Pawel DROŹDZIEL, prof. PL works at the Institute of Transport, Combustion Engines and Ecology of Faculty of Mechanical Engineering of Lublin University of Technology, Vice-Rector of this university. Prof. Droźdiel focuses his research activities mainly on solving problems in the field of tribology, durability and safety technical systems. 